\title{
Strategies To Enhance Teaching And Learning In A Rapidly Changing Economy
}

Seet M.K., (E-mail: seetminkok @sim.edu.sg), Singapore Institute of Management, Singapore

\begin{abstract}
The Singapore economy is undergoing rapid structural changes with new industries emerging while old industries slow down. This means that workers have to constantly acquire new knowledge and skills to take on the new challenges in the economy. Teaching and learning in a changing economy takes on a new perspective in the light of a rising number of adult learners who work by day and become students in the evening. This paper examines the different strategies that lecturers could implement to enhance their teaching and facilitate students in their learning experiences.
\end{abstract}

\section{INTRODUCTION}

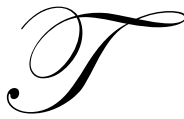

he rising emergence of Singapore as a global education hub in recent years has been accompanied by a growing recognition that learning has to be tailored to the needs of the changing economic landscape. The rapidly changing job market in Singapore, which underlies structural changes in the economy, emphasises the need for versatility, adaptability and flexibility of worker skills. One of the important challenges faced by a tertiary institution is in the area of effective teaching methodologies aimed at helping students to learn proficiently and in equipping them with dynamic skill competencies to meet the vagaries of the changing work environment. This paper examines the different strategies that lecturers in higher education could implement to enhance their teaching as well as explore various ways that lecturers can assist students in their learning experiences.

\section{CHANGING CHARACTERISTICS OF THE SINGAPORE LABOUR MARKET}

The Singapore economy has gone through significant changes over the last few decades. The phase of rapid economic expansion from the 1970s to the mid 1990s is over. Globalisation coupled with the emergence of China and the 1997 Asian Financial Crisis have conspired to fundamentally change the global economic environment. Corporate restructuring and downsizing, which began since the early 2000s, is still going on albeit at a slower pace. This has resulted in a large pool of Singapore workers who are structurally unemployed. This problem not only affects the older, less skilled workers who hold below-secondary qualifications, but it also affects the better-educated whitecollar professionals. Indeed, unemployment, particularly of adult workers, is one of the main challenges facing the Singapore workforce today.

Table 1

Quarterly and Annual Unemployment Rates (\%), 1997 - 2004

\begin{tabular}{|c|c|c|c|c|c|c|c|c|}
\hline Resident Unemployment Rate & $\mathbf{1 9 9 7}$ & $\mathbf{1 9 9 8}$ & $\mathbf{1 9 9 9}$ & $\mathbf{2 0 0 0}$ & $\mathbf{2 0 0 1}$ & $\mathbf{2 0 0 2}$ & $\mathbf{2 0 0 3}$ & $\mathbf{2 0 0 4}$ \\
\hline Annual Average & 2.0 & 3.5 & 3.8 & 3.7 & 3.8 & 4.9 & 5.3 & 4.5 \\
\hline Seasonally Adjusted & & & & & & & & \\
Mar & 1.9 & 2.4 & 4.3 & 3.8 & 2.6 & 5.1 & 5.1 & 5.2 \\
Jun & 1.9 & 2.7 & 3.9 & 4.9 & 3.2 & 4.9 & 5.1 & 5.0 \\
Sep & 1.8 & 4.3 & 3.8 & 2.7 & 3.9 & 4.7 & 6.1 & 3.9 \\
Oct & 2.1 & 4.5 & 3.2 & 3.1 & 5.2 & 4.9 & 5.0 & 4.0 \\
\hline
\end{tabular}

Source : Ministry of Manpower 
The changing global environment brought about structural changes to the industries in Singapore, with significant impact on the requirements for labour demand. The manufacturing sector, which employed $28 \%$ of the Singapore workforce in 1992, hired merely18\% of the workforce in 2002. By contrast, hirings in the services sector rose steadily over the same period, with the services share of total employment expanding from $65 \%$ in 1992 to $75 \%$ in 2002. The share of employment in the other sectors of the economy remained relatively constant over the period 1992-2002. This is shown in the following table:

Table 2

Share of Employment By Economic Sectors

\begin{tabular}{|l|c|c|}
\hline Sector & $\mathbf{1 9 9 2}$ & $\mathbf{2 0 0 2}$ \\
\hline Manufacturing & $28 \%$ & $18 \%$ \\
\hline Services & $65 \%$ & $75 \%$ \\
\hline Others (Including construction) & $7 \%$ & $7 \%$ \\
\hline
\end{tabular}

Source: Ministry of Trade \& Industry ${ }^{2}$

More importantly, an adverse trend has developed in the midst of the structural changes in the economy. Singapore lags behind other developed countries such as the US, UK and Japan in the educational profiles of its workforce. In particular, there is a lack of skilled knowledge workers and managerial talent at the top end of the labour force. In 2001, only $17 \%$ of the Singapore workforce holds degree qualifications compared to $18 \%$ - $27 \%$ of the labour force who hold degree qualifications in the developed countries like U.S. Japan and U.K. Moreover, there is also a large pool of workers in Singapore who lack formal qualifications and require training and upgrading. In 2001, about one-third of the labour force hold below-secondary qualifications compared to significantly lower percentages in the major developed economies. These comparisons are summarised in the following table:

Table 3

Educational Profile of Labour Force By Qualification Levels, 2001

\begin{tabular}{|l|c|c|c|}
\hline Country & Degree & $\begin{array}{c}\text { Secondary and post } \\
\text { secondary }\end{array}$ & Below secondary \\
\hline US & $27 \%$ & $60 \%$ & $13 \%$ \\
\hline Japan & $20 \%$ & $62 \%$ & $17 \%$ \\
\hline U.K. & $18 \%$ & $70 \%$ & $12 \%$ \\
\hline S. Korea & $17 \%$ & $51 \%$ & $31 \%$ \\
\hline Singapore & $17 \%$ & $49 \%$ & $34 \%$ \\
\hline Hong Kong & $16 \%$ & $67 \%$ & $17 \%$ \\
\hline
\end{tabular}

Source : Economic Review Committee Report (2003) ${ }^{3}$

\section{CONTINUING EDUCATION FOR A STRONG WORKFORCE}

It is an undeniable fact that Singapore's future depends upon a workforce of highly trained people for whom constant improvement of skills and educational qualifications is the only way of ensuring continued employability. The need for constant upgrading of skills was highlighted by the Deputy Prime Minister and Minister-in-Charge of Tertiary Education, Dr. Tony Tan Keng Yam, in early 2001 when he remarked: “...education will be the key distinguishing factor between countries which do well in the $21^{\text {st }}$ century and those which do not. We need to strengthen education at every level.... Our universities need to continually re-examine their roles to ensure that what they offer is relevant and useful."

The link between education and economic improvement is well recognised. Education needs to prepare learners to participate constructively in the economic development of their societies and to provide a means for equipping workers to take on new challenges in an evolving economy. Economies such as Singapore are faced with a number of issues that concern the cultural complexity of their societies, the need to maintain conditions for creativity and high quality performance, the continued demand for scientific and technological excellence and the changing 
nature of employment opportunities. In such contexts, educational processes must respond to the diversity of needs of learners and make sure that the best opportunities for lifelong learning are available for all.

\section{WAYS TO ENHANCE TEACHING \& LEARNING IN TERTIARY INSTITUTIONS}

Teaching and learning takes on a focussed perspective in the context of the development of a rigorous educational system to cater to the needs of globalisation and lifelong employability. In the Singapore case, where a growing number of students are people who have permanent jobs during the day and come in the evening to further their knowledge and learn new skills, lecturers in the tertiary institutions may have to look at innovative ways of teaching in their deliveries. This, of course, presupposes that lecturing skills can be honed and improved upon. As T.J. Pear ${ }^{5}$ puts it, "the technique of imparting knowledge in the special way called lecturing can be learned and improved upon".

Brown and Atkins ${ }^{6}$ (1988) suggest that there are 4 key element to strong lecturing skills:

- $\quad$ Explaining materials clearly

- $\quad$ Generating student interests

- $\quad$ Making persuasive arguments

- $\quad$ Varying student activities

\section{Explaining Materials Clearly}

Explaining involves giving understanding to another person. Good explanations therefore entail that the listener ought to be able to understand completely what is mentioned by the speaker. We could analyse the explanation process as a journey which encompasses the following three stages:

$\begin{array}{lll}\text { - } & \text { A problem arises } & \text { (Problem identification) } \\ \text { - } & \text { Series of statements } & \text { (Transmission) } \\ \text { - } & \text { Understanding of the problem } & \text { (Outcome })\end{array}$

Essentially, the 3-part process begins with the explainer identifying the appropriate problem to be examined. $\mathrm{He} / \mathrm{she}$ then articulates a series of statements to explain the problem. Finally, the explainer would attempt to understand whether his/her explanation has been clearly understood.

There are several implications of this 3-part process in explaining:

- $\quad$ Explainer must take account of both the problem and likely knowledge of the listening audience. This issue is particularly important in the context of lifelong learning and continual education. For example, the explanation of the concept of "oligopoly" to a clerical worker would be different from that to a third-year microeconomics student.

- Explainer must know what the problem is and what he is trying to explain. This is often overlooked in the midst of the vast sea of knowledge that the internet age has opened up our minds to. The explainer therefore needs to be focussed on the subject that he/she wants to explain.

- $\quad$ Outcome of understanding can be monitored by lecturer through eye contact and checking students' reaction. This is to constantly ensure that the materials taught by the lecturer are well understood by the students. Any doubts or questions could be clarified immediately so that students can progress smoothly to higher levels of learning and understanding.

G.A. Brown ${ }^{7}$ (1979) has suggested 4 structures to bring about clear explanations. These 4 structures to clear explanations are briefly discussed below:

- $\quad$ Signposts - Statements that signal the directions and structure of a lecture. For example, if there are 4 issues to be discussed in a lecture, one could start by saying that "Today, I want to examine 4 issues. The first 
issue is ... The second issue is .....The third issue is ... Finally, ..”. By clearly marking out the various signposts in the educational journey, the lecturer is able to guide the students through each stage of the learning process thereby facilitating student understanding.

- $\quad$ Frames - Statements which delineate the start and end of topics or sub-topics. For example, at a particular juncture during a lecture, the lecturer who wants to turn to another area of discussion could say "Let's turn now to supply curve. By supply curve, I mean ...". Frames are useful in helping students to classify issues clearly, so as to avoid confusion when many issues are being discussed in a lecture.

- $\quad$ Foci - Statements which highlight and stress key points. For example, to emphasize an important point or concept, the lecturer could say "The basic principle underlying free markets is this (pause)". Such statements serve to reiterate significant issues that arise during a lecture which the lecturer would like students to focus their attention on.

- $\quad$ Links -Statements which link sections of lecture together. For example, to draw a link between 2 issues, the lecturer could indicate that "The above explanation implies that ...". Such links help to show the relationship between issues, particularly on difficult topics which students might encounter problems in comprehending.

Apart from the above 4 structures (proposed by Brown), some basic principles to clear explanations should not be overlooked as well. This is particularly important for an audience who are workers by day and learners in the evening. These workers could be pretty tired after a hard day's work by the time they attend the lecture in the evening. Their ability to concentrate throughout the lecture could also be substantially compromised. In light of these drawbacks, the lecturer could consider the following pointers to clear explanations in his delivery:

- $\quad$ Speak clearly, use pauses, don't go too fast

- $\quad$ Plan, prepare and structure to deliver a clear, simple view

- $\quad$ Clarify and emphasize key points

- $\quad$ Observe student reaction

- $\quad$ Do not try to cover everything

- $\quad$ Lecturer must ensure that he knows his/her own materials

\section{Generating student interest}

Generating student interest takes on an added dimension in the context of continual education and learning, which Singapore workers are having to face today. Gone are the days when workers could learn a single skill or trade and be employed for life in their chosen field of study. Today, workers find that they have to constantly upgrade and learn new things in order to remain employable for life.

The challenge for lecturers is how to constantly stir student interests on new/evolving issues so as to continuously engage the students in their learning. Generating student interest is crucial to student learning because:

- $\quad$ Self-motivation for student - Students who are interested to learn will be motivated to hunger for knowledge. This hastens the learning process and creates fun in learning.

- $\quad$ Long-term influence on student (even after lecture contents are forgotten) - Students who have a strong interest in certain areas could eventually pursue further studies in related fields, thereby enhancing their employment prospects. By contrast, students who have little interest in a given field are unlikely to followup on their learning in those areas.

There are a variety of methods to generate student interests:

- Use of gesture, eye contact, and vocal inflection can increase expressiveness - Quite often, the captivating lecturer is someone who is able to combine these attributes to good effect during the lecture

- $\quad$ Apt use of examples and analogies that have personal applications or relevance to daily lives - Working adults have many experiences to share in their daily lives/work. It would be refreshing for students if lecturers are able to tie in their learning to their daily experiences. 
- Use of appropriate mode of explanation :

o Conceptual - This involves providing a series of facts or concepts in a logical order

o Anecdotal - This involves providing relevant anecdotes or examples which can be entertaining to the audience

o Narrative - This involves explaining an event or issue in the form of a personal story (by the lecturer)

In the context of adult learners, it is useful for the lecturer to consider the following pointers associated with generating student interest:

- $\quad$ Show own interest/commitment to topic

- $\quad$ Think of and use examples, analogies, and models which are apt for the audience and the topic

- If the material is unfamiliar, begin with several examples

- Use a combination of modes of explanation, especially the narrative mode

- $\quad$ Play on the intellectual curiosity of the audience through the use of puzzles, problems and questions

At times, the lecturer could inadvertently make comments, which diminish the interest of the students. $\operatorname{Meier}^{8}(2000)$ have suggested some negative comments to avoid in the light of generating student interests:

- We have tons of materials to cover but not much time today

- $\quad$ The topic we are covering today is very difficult and extremely complicated to understand

- I know this is boring, but try to stay with it

- If you don't learn this, you will not be able to find a job

- $\quad$ You've got to remember these 8 steps

- $\quad$ This may not make sense to you, but try to learn it

\section{Persuasive Arguments}

Persuasive arguments are important in lectures for two reasons:

- $\quad$ It affects quality of the overall presentation - Students who are persuaded by the arguments of the lecturer will likely feel that they have benefited from a good presentation. Conversely, students who could find many loopholes or weaknesses in a presentation will likely be sceptical of the views/issues expressed.

- It helps students in interpreting conflicting theories and understanding underlying assumptions - Quite often, the lecturer has to discuss various theories or hypotheses which might conflict with one another. The task is especially challenging when the audience is a group of working adults who are exhausted at the end of the day and whose attentiveness during the lecture is substantially compromised by work fatigue. This is where persuasive arguments can make a difference in helping the students to distinguish clearly between conflicting theories and their underlying assumptions.

In lecturing, it is arguable that persuasion hinges crucially on the effective use of rhetoric. Atkinson ${ }^{9}(1984)$ suggests that there are a variety of rhetorical devices that politicians use to persuade others to accept certain viewpoints. One such device, which is relevant to lecturing, is the use of pairs of contrasting statements. In highlighting the contrast between two opposing statements, the lecturer is often able to convincingly show a clear distinction between two views, and more readily persuade the listener to a particular viewpoint. Another possible tool in persuasive argument is the use of deductive arguments. On the whole, even the most critical listener would find it hard not to be persuaded by sound deductive arguments. Finally, arguments can be more persuasive if they are appealing and interesting. The audience is more likely to focus on the topic and be more persuaded to listen intently if the topic discussed is appealing to them and interestingly put across by the lecturer. Conversely, a boringlydelivered lecture is unlikely to hold the audience's attention for long, let alone persuading them about a particular viewpoint. 
Studies by Zimbardo, Erbeson and Maslach ${ }^{10}$ (1977) highlight a number of important principles in persuasive explaining which the lecturer could take note account while delivering his/her lecture:

- Know your audience and assess what kinds of arguments may be appealing/interesting to them - This follows directly from what is discussed above, whereby the audience is more likely to be captivated and persuaded about a particular viewpoint if the argument is appealing.

- $\quad$ Audience is more likely to listen and accept your views if you are perceived as credible and possess expertise in the area (that you are lecturing on) - For example, a mathematics professor might appear unconvincing in delivering a lecture on poetry appreciation.

- When there are arguments for and against a particular view, it is good to present both sides - This provides a more balanced approach to issues rather than a partial or segmented view, which is less likely to go down well with the audience.

- $\quad$ Mention what experts would say when faced with the problem that you are discussing - As lecturers (in all honesty) cannot be expected to know everything about a particular topic or subject, it is sometimes useful to quote the viewpoints or experiences of experts when addressing certain contentious issues/problems. This provides a good basis for teaching (adult learners) in showing that learning is not an end in itself, but rather a journey/process that requires constant thinking and reflection on the ideas that they gather during the lectures.

- If your suggestions are likely to be challenged, describe opposing view and show its weaknesses - This is useful in pre-empting negative criticisms that could demolish the persuasive arguments that the lecturer could have assiduously built up in the course of his/her delivery.

\section{Varying Student Activities}

A two-hour lecture does not necessarily mean that the lecturer has to talk profusely for two whole hours. Varying student activities during the lecture would be useful due to the following benefits:

- $\quad$ It renews student attention

- It reinforces student interests in the topic

- $\quad$ It provides opportunities for students to think

- $\quad$ It enables some student feedback on their understanding

Some lecturers might argue that varying student activities is a waste of time, especially for matured adult learners, because they will not participate in those activities anyway. The immediate response to this criticism is that learning can be undertaken in various ways. Participation in certain activities can also a form of learning if the activities foster one's understanding on issues and concepts.

Yet other lecturers might fear that when they introduce activities in a lecture, they might lose control of the class. This problem can be overcome by effective time management on the part of the lecturer. Thus, in managing the time for each activity, the lecturer could signal the start and end times of each activity so that students are clear about what need to be accomplished when they go about undertaking the tasks assigned during the time allocated.

There are a variety of ways in varying student activities during the lecture. The following are some suggestions to vary student activities, which include proposals by Bligh ${ }^{11}$ (1986) and Gibbs, Habeshaw and Habeshaw $^{12}$ (1983):

- $\quad$ Set a question or problem to be discussed in buzz groups. Buzz groups are useful because they are not time consuming and they provide students with a short break so that they can return to listening and not-taking with renewed concentration. This is especially beneficial to working adult learners whose tired minds need periodic breaks to learn effectively. 
- Show a video clip - with clear instructions on what to look for. Video clips can also serve as an interesting alternative mode of learning compared to the face-to-face lecture, especially on subject matters that are sometimes straightforwardly monotonous.

- $\quad$ Organize students to give group presentations on certain questions set by the lecturer. Group presentations are useful in encouraging discussion among students and allowing them to share their learning experiences.

- $\quad$ Set a simple test or assessment for the students to be attempted during the lecture. This could also serve as a means of testing whether the students have been able to understand what is taught during the preceding lectures.

- Demonstrate an experiment - with instructions on what to look for. This could be relevant for subjects where experiments can be performed e.g. in physics or chemistry.

\section{CONCLUSION}

As continual learning becomes increasingly important in a rapidly changing economy, the challenge for lecturers is to ensure that their teaching remains effective in helping working adult learners acquire new skills and knowledge. Effective lecturing skills encompasses the need to make clear explanations in their delivery, generate student interests in the topics taught, make persuasive arguments to help students understand, and vary student activities to make learning more fun and enjoyable. A balanced approach to applying these 4 pillars of lecturing skills would go a long way towards enabling the lecturer to teach more effectively and better facilitate learning among students.

\section{ENDNOTES}

1. Report on the Labour Market, 4th Quarter, 2004 published by the Ministry of Manpower (Singapore)

2. Annual GDP data published by the Singapore Department of Statistics, Ministry of Trade \& Industry

3. Report by the Economic Review Committee New Challenges, Fresh Goals (2003)

4. Dr. Tony Tan Keng Yam, Deputy Prime Minister and Minister for Defence at the NUS Political Association Ministerial Forum held on Friday, 16 February 2001

5. $\quad$ Pear, T.J. (1933) The Psychology of Effective Teaching, London: Kogan Page

6. Brown, G.A. and Atkins, M.J. (1988) Effective Teaching in Higher Education, London: Routledge

7. Brown, G.A. (1979) Learning from Lectures, Nottingham: University of Nottingham Press

8. $\quad$ Meier, D. (2000) The Accelerated Learning Handbook, McGraw-Hill

9. Atkinson, M. (1984) Our Master's Voice, London: Methuen

10. Zimbardo, P., Erbeson, E., and Maslach, C., (1977) Influencing Attitudes and Changing Behaviour, Massachusetts: Addison-Wesley

11. Bligh, D. A. (1986) Teach Thinking through Discussion, London: NFER-Nelson

12. Gibbs, G., Habeshaw, S., and Habeshaw, T. (1983) Interesting Things to do in Your Lectures, Bristol: Technical and Educational Services Ltd. 


\section{NOTES}


1. Report on the Labour Market, 4th Quarter, 2004 published by the Ministry of Manpower (Singapore)

2. Annual GDP data published by the Singapore Department of Statistics, Ministry of Trade \& Industry

3. Report by the Economic Review Committee New Challenges, Fresh Goals (2003)

4. Dr. Tony Tan Keng Yam, Deputy Prime Minister and Minister for Defence at the NUS Political Association Ministerial Forum held on Friday, 16 February 2001

5. Pear, T.J. (1933) The Psychology of Effective Teaching, London: Kogan Page

6. Brown, G.A. and Atkins, M.J. (1988) Effective Teaching in Higher Education, London: Routledge

7. Brown, G.A. (1979) Learning from Lectures, Nottingham: University of Nottingham Press

8. Meier, D. (2000) The Accelerated Learning Handbook, McGraw-Hill

9. Atkinson, M. (1984) Our Master's Voice, London: Methuen

10. Zimbardo, P., Erbeson, E., and Maslach, C., (1977) Influencing Attitudes and Changing Behaviour, Massachusetts: Addison-Wesley

11. Bligh, D. A. (1986) Teach Thinking through Discussion, London: NFER-Nelson

12. Gibbs, G., Habeshaw, S., and Habeshaw, T. (1983) Interesting Things to do in Your Lectures, Bristol: Technical and Educational Services Ltd. 